\title{
Computerized cognitive training to improve mood in senior living settings: design of a randomized controlled trial
}

This article was published in the following Dove Press journal: Open Access Journal of Clinical Trials

\author{
Marianne Smith' \\ Michael P Jones ${ }^{2}$ \\ Megan M Dotson' \\ Fredric D Wolinsky ${ }^{3}$ \\ 'College of Nursing, The University of \\ lowa, lowa City, IA, USA; '2Department \\ of Biostatistics, College of Public \\ Health, The University of lowa, lowa \\ City, IA, USA; '3 Department of Health, \\ Management and Policy, College of \\ Public Health, the University of lowa, \\ lowa City, IA, USA
}

Purpose: This two-arm, randomized controlled trial was designed to evaluate a computerized cognitive speed of processing (SOP) training known as Road Tour in the generally older group of adults residing in assisted living (AL) and related senior housing. Study aims focused on depression-related outcomes that were observed in earlier SOP studies using Road Tour with younger, home-dwelling seniors. Study design and baseline outcomes are discussed.

Participants and methods: A community-based design engaged AL and related senior living settings as partners in research. Selected staff served as on-site research assistants who were trained to recruit, consent, and train a target of 300 participants from $\mathrm{AL}$ and independent living (IL) programs to use the intervention and attention control computerized training. Ten hours of initial computerized training was followed by two booster sessions at 5 and 11 months. Outcome measures included Useful Field of View, 9-item Patient Health Questionnaire, 12-item Centers for Epidemiological Studies Depression scale, 7-item Generalized Anxiety Disorders, Brief Pain Inventory, and SF-36 Health Survey. Assessments occurred before randomization (pretraining) and posttraining, 26 and 52 weeks.

Results: A total of 351 participants were randomized to the intervention $(n=173)$ and attention control $(n=178)$ groups. There were no significant differences between groups in demographic characteristics, with the exception of education and reported osteoporosis. There were no significant differences in study outcomes between groups at baseline. Participants in AL had significantly lower SOP and self-rated health, and significantly higher depression, anxiety, and pain when compared to those in IL programs on the same campus.

Conclusion: Compared to earlier SOP training studies using Road Tour, this sample of senior living participants were older, reported more health conditions and poorer overall health, and had lower Useful Field of View scores and greater depressive symptoms at baseline. Moreover, participants in AL had greater health challenges than those in IL.

Keywords: speed of processing, depression, assisted living, community-based design

\section{Introduction}

Depression is a large, escalating public health problem that is the leading cause of disability worldwide, and a major contributor to the overall burden of disease. ${ }^{1}$ Depression among older adults is often related to other comorbidities including anxiety, pain, medical illness, cognitive decline, and functional impairment, which further contribute to a disability spiral that threatens independence and health-related quality of life (HRQoL). ${ }^{2-4}$ Late-life depression is also very costly to individuals and society, with health care costs for depressed elders exceeding that of nondepressed ones in every category. ${ }^{5}$
Correspondence: Marianne Smith College of Nursing, The University of lowa, 50 Newton Road, CNB, lowa City, IA 52242, USA

$\mathrm{Tel}+\mid 3193357121$

Fax +l 3193535535

Email marianne-smith@uiowa.edu 
The prevalence of late-life depression among older adults who reside in assisted living (AL) and related senior living settings poses important challenges and concerns. Reports suggest $22 \%-30 \%$ of residents in $\mathrm{AL}$ and related settings have depressive symptoms, ${ }^{6-8}$ but recognition and treatment is often low. ${ }^{9-12}$ The homelike features of residential senior living settings have attracted an increasingly physically and mentally frail group of elders, ${ }^{13-16}$ but services have not always kept pace with health-related demands. Many elders receive health care as if they were living at home, a model that relies on the older person to self-manage their health conditions with minimal oversight or assistance. Personal care attendants who provide most services are often not trained to recognize health problems or know what to do in response, especially for mental health issues. ${ }^{10,12}$ Although support for depression recognition and use of public health approaches like exercise and activity engagement are increasingly available, ${ }^{17}$ alternative depression prevention and treatment approaches are needed. ${ }^{18-20}$

A computerized cognitive training intervention known as Road Tour has demonstrated considerable promise as a novel depression treatment alternative for older adults living at home. The training intervention, which plays like a game, was developed to improve cognitive function and delay cognitive decline in older adults. However, the Advanced Cognitive Training for Vital Elderly (ACTIVE) study also demonstrated that Road Tour provided protection against worsening depressive symptoms ${ }^{21}$ and the onset of suspected clinical depression. ${ }^{22}$ Moreover, data from the Iowa Healthy and Active Minds Study (IHAMS) ${ }^{23}$ indicated that Road Tour also reduced existing levels of depressive symptoms among community-dwelling participants aged 50-87 years old. Although the mechanism of action for speed of processing training (SOPT) on depressive symptoms is unclear at this time, psychological and biological processes are both possible. First, SOPT has also shown a positive impact on HRQoL, ${ }^{24}$ which may, in turn, improve mood. As the person feels and functions better, their mood also improves. Second, SOPT may alter neurological function in the brain that influences or controls mood, an explanation that is consistent with neuroplasticity theory and evidence. ${ }^{25}$ For now, the earlier studies provide considerable support for evaluating the effect of Road Tour on depressive symptoms among the generally older and more functionally challenged group of older adults who have chosen to live in supported residential living environments like $\mathrm{AL}$.

As a self-directed, user-friendly computer "game," Road Tour overcomes many of the challenges that impede detection and treatment of depressive symptoms in AL settings. There is no need to recognize depressive symptoms, find qualified providers, make referrals, or arrange transportation. The focus on "gaming" avoids potentially stigma-ridden discussions of depression or resistance to "getting help." Road Tour has no known negative side effects, no known adverse "interactions" with other treatments, and can be used by anyone who has adequate vision and can use a keyboard and mouse. In short, the program offers an important opportunity to promote health and quality of living by interrupting the downward spiral of depression and related disability.

The purpose of this paper is to describe the study methods for a two-arm, randomized controlled trial (RCT) that evaluated Road Tour in AL and related senior living settings. Adaptations to planned approaches are described, along with participant characteristics and baseline outcomes for our three specific aims to evaluate the effect of Road Tour vs attention control on: 1) cognitive processing speed in the AL setting; 2) reducing depressive symptoms and the risk of onset of suspected clinical depression in the AL setting; and, 3) depression-related comorbidities including anxiety, pain, and HRQoL in the AL setting. In this paper we describe the study plan and relevant adaptations, and then describe baseline outcomes.

\section{Materials and methods}

The study, Improving Mood in Assisted Living Settings Using a Cognitive Training Intervention (R01 NR-013908; funded by the National Institute of Nursing Research, NINR) was a 5-year, two-arm, parallel, RCT comparing Road Tour training to attention control training using computerized crossword puzzles. Independent Review Board approval was obtained and maintained from the University of Iowa. Written informed consent was obtained from participants. The study was registered with Clinical Trials.gov (NCT 01763216).

\section{Setting recruitment and engagement}

A community-based research approach was used to engage AL settings as partners in conducting the research project. The goal was to engage up to $30 \mathrm{AL}$ settings that would each recruit a minimum of 10 older adult participants to achieve the target of 300 total participants. As partners in the research, each organization identified one or more staff members who completed university-sponsored, online human subjects training and acted as on-site research assistants (RAs). These on-site RAs, called Study Liaisons, were trained to recruit, consent, and train participants to use the computer games, conduct computer-based assessments, and facilitate 
telephone assessments conducted by university team members. Study Liaison preparation used detailed training manuals and fidelity checks performed by the Study Coordinator to assure the integrity of study procedures at partner sites.

\section{Adaptation to setting type}

Although AL programs were plentiful, the vast majority were too small to identify 10 participants who would participate, and/or did not have staff resources to support the participatory study approach. Moreover, senior living leaders questioned the logic of involving only AL residents, noting that many residents on the same campus were "one service away" from being classified as "assisted" based on their age, health, and function. Others indicated that they had abandoned policies that required residents to relocate when they needed services. In turn, many older adults living in housing that was defined as "independent living" (IL) on their campus were receiving personal assistance similar to those living in housing defined as AL. As a result, older adults residing in IL apartments on senior living campuses whose AL services were also involved in the study were also invited to participate.

\section{Study participants}

All older adults living at partner sites were invited to enroll to maximize generalizability. Inclusion/exclusion criteria included being 60 years old or older, residing in a participating AL, speaking English (the language of Road Tour), and self-report having sufficient visual acuity (with glasses) to use a computer, physical ability to operate a computer keyboard and mouse, and capacity to provide informed consent. Written informed consent was obtained by Study Liaisons at each site using standard procedures that were modeled by university team members to assure both comfort with the process and fidelity to the methods.

\section{Adaptation to participants}

We adjusted the lower boundary of our inclusion criteria to 55 years to conform to admission policies in partner settings. This adjustment allowed the Study Liaisons to avoid a sense of discrimination against slightly younger adults living in their communities, and greatly simplified their advertising and recruitment approaches.

\section{Experimental design}

Figure 1 contains the CONSORT Flow Chart for the study. Eligible older adults who completed informed consent with Study Liaisons were scheduled for baseline telephone interviews conducted by university team members. All primary outcome measures were collected via telephone interviews, except for the speed of processing measure which was collected on-site by Study Liaisons. Randomization occurred after baseline interviews were completed. Participants were

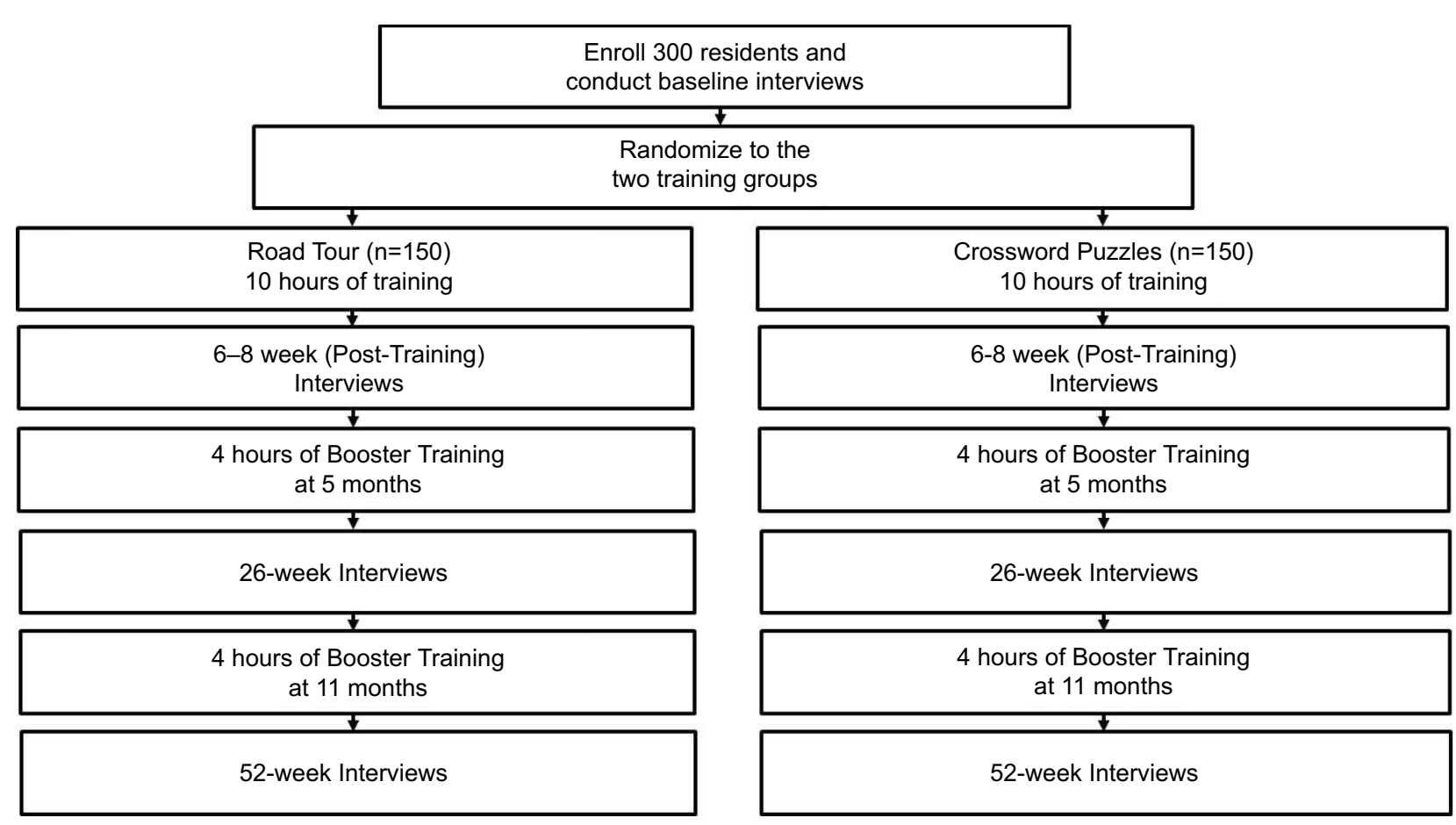

Figure I CONSORT flow chart. 
asked to complete 10 hours of training during the first 5-6 weeks, and 4 additional hours of training at 5 and 11 months for a total targeted dose of 18 hours.

\section{Randomization}

Participants were randomized to training groups using block randomization within sites and types of care (AL and IL) to maintain balance across treatment conditions by senior living community and residence type (AL and IL). The study statistician determined the order of assignments using a computer-generated list of random numbers using block sizes of two and four. Participant IDs and assignments were concealed in sequentially numbered opaque envelopes stored in separate bins (one for each site) kept in a locked cabinet within the Study Coordinator's office.

\section{Assessment and data management}

Computer-assisted telephone interviews were used to assess participant characteristics and outcome measures at baseline, and outcome measures again at posttraining (6-8 weeks postrandomization), and at 26 and 52 weeks post-randomization. The speed of processing assessment was administered at the four time points by Study Liaisons using study computers at partner sites. Usage information embedded in the intervention software was sent to research investigators over the internet using secure file encryption protocols. This included the number of minutes played, number of sessions, and the percentage of completing all available exercise sets.

All data collection was monitored by the Study Coordinator. Standard procedures were used for programming computer-assisted telephone interviews software, interviewer training, data entry and editing, as well as database management, updating, reconciliation, data retrieval, and statistical computing, and data security and confidentiality. Codes were written so that missing and implausible values were automatically flagged in real time during the interviews for verification when entered. On-site speed of processing assessments were saved using participant ID numbers and copied to encrypted flash drives that were mailed to the Study Coordinator. Results were printed first and then entered electronically, with the printed originals kept in secure storage. All data were stored on a secure university server that is backed up daily and uses a three-tiered authorization and strong password system to protect data.

\section{Instruments and measures}

\section{Speed of processing measures (Aim I)}

Speed of processing was measured using the Useful Field of View (UFOV) PC mouse version. The UFOV is well established, has high reliability and validity, and is the gold standard for measuring visual processing speed. ${ }^{26}$ It is computer administered and takes 5-7 minutes to complete. Three subtests, stimulus identification, divided attention, and selective attention, are each automatically scored from 17-500 miliseconds (ms), reflecting the shortest exposure time at which the participant could correctly perform each subtest $75 \%$ of the time. A composite outcome score of the three subtests ranges from 51 to $1,500 \mathrm{~ms}$, with lower scores reflecting faster speed of processing. Normative data for 2,759 participants aged 65-94 years in the ACTIVE clinical trial indicates that the baseline UFOV composite scores ranged from 86 to $1,500 \mathrm{~ms}$, with a mean of $481.9 \mathrm{~ms}$ and standard deviation of $247.5 \mathrm{~ms}^{27}$

\section{Depression symptoms (Aim 2)}

The frequency and severity of depression symptoms were assessed using two self-report scales that were used at each time point. The 12-item version of the Centers for Epidemiological Studies Depression (CESD) scale ${ }^{28}$ is a shorter version of the original CESD-20 ${ }^{29}$ that has been a gold standard for screening for depression in epidemiological and public surveys, and has very high reliability and validity. The CESD-12 was used in both ACTIVE and IHAMS trials which allows comparison of depression outcomes among participants in this study and subjects in earlier studies. CESD-12 is composed of short statements scored from $0=$ rarely or none of the time $(<1$ day per week) to $3=$ all of the time $(5-7$ days per week) for a score range of $0-36$, and has a cut-off score of $\geq 9$ for suspected clinical depression. ${ }^{21,22,30}$

The 9-item Patient Health Questionnaire (PHQ-9) ${ }^{31}$ also has very high reliability and validity, is widely used in both research and clinical settings, and performs well in telephone assessments. ${ }^{32,33}$ The PHQ-9 items reflect the nine DSM-5 diagnostic criteria for major depression ${ }^{34}$ and are rated from $0=$ not at all to $3=$ nearly every day for a total score range of 0-27. Established cut-points are: 0-4= minimal depression; 5-9 = mild depression; $10-14=$ moderate depression; $\geq 15=$ severe depression. Scores $\geq 10$ indicate clinically significant depression. ${ }^{35}$ The PHQ-9 directly assesses two hallmarks of major depression (prominent dysphoria and anhedonia) and is described in a large body of late life depression research.

\section{Depression-related health outcomes (Aim 3)}

HRQoL, pain, and anxiety measures used in the study have well-established reliability and validity and age-specific national norms for comparative purposes. HRQoL was measured using the Short Form-36 (SF-36) Health Survey ${ }^{36}$ at baseline and 52 months to allow direct comparison of 
1 -year effects with IHAMS and ACTIVE studies. The shorter SF- $12^{37}$ was used at 6-8 and 26 weeks to approximate SF-36 scores at these intermediate assessments while minimizing respondent burden. Both the SF-12 and SF-36 include the standard single item self-rated health question. Pain was assessed using the Brief Pain Inventory (BPI) that was developed for assessing cancer pain, validated for use in general populations, and is widely used. ${ }^{38-40}$ The BPI includes four pain severity and seven pain interference items that are rated from 0 to 10 , an open-ended pain severity item that is rated 0 to 10 , two open-ended questions about use of medications and treatments used to treat pain, and one question about pain relief from treatments that is rated 0 to 10 . Anxiety symptoms were assessed using the 7-item Generalized Anxiety Disorder (GAD-7) scale ${ }^{41}$ that rates the DSM-IV ${ }^{42}$ criteria for GAD on a scale from $0=$ not at all to $3=$ nearly every day. Cut-points for the GAD-7 are comparable to the PHQ-9, with $0-4=$ minimal anxiety; 5-9 = mild anxiety; and $\geq 10=$ clinically significant anxiety.

\section{Covariates}

Personal and health-related characteristics were collected at baseline. Personal characteristics included sociodemographic data (age, race, sex, marital status, education, and income), social support (five items scored on a 5-point scale from $0=$ none to $4=$ all of the time), and presence of common chronic conditions like high blood pressure, arthritis, heart disease, diabetes, lung disease, as well as anxiety disorder, depression, and current use of depression treatments. Characteristics of partner organizations included number of older adults served, type of programs and services provided, type and number of staff employed, profit/ownership status, and years in operation.

\section{Intervention and attention control training programs \\ Intervention}

Road Tour is the second-generation SOPT program that was evaluated in ACTIVE (in its MS-DOS format) and used in IHAMS (in its MS Windows format). The training was designed to improve the efficiency and accuracy of visual information processing and the ability to perform complex visual attention tasks. It focuses on improving the speed and accuracy with which users identify and locate visual information using a divided attention format. Over time, the difficulty and complexity of each task is systematically increased as users attain specified performance criteria. Difficulty is increased by reducing visual stimuli duration, adding visual distracters, increasing similarity between target and distracter stimuli, and presenting visual targets over a broader spatial expanse.

To initiate training, the user clicks on the start button. One of two vehicles, either a car or a truck, appears in the center of the screen. Seven distracter stimuli (rabbit crossing signs) and the target sign (Route 66) appear in the periphery. The stimuli (car vs truck, and rabbit crossing vs Route 66 sign) are presented for a specified time and then disappear briefly. A car and truck appear, and the user clicks on the correct target vehicle (car or truck). Then the user selects the circular location where the Route 66 sign had appeared. The training program is tailored to the participant's performance by maintaining a $75 \%$ success rate before increasing the challenge level. As the user progresses, three changes increase the task difficulty: the visual field expands; an increasing number of distracters appear; and the vehicle pairs morph to become more similar and thus more difficult to differentiate.

\section{Adaptation to the intervention}

Posit Science Corporation's CD-ROM based Road Tour training program was used until support was unexpectedly discontinued in August 2014, approximately 17 months after starting enrollment. The web-based replacement, Double Decision, (https://www.brainhq.com/why-brainhq/aboutthe-brainhq-exercises/attention/double-decison) was used from 2014 through the end of enrollment in 2015. The training features of Double Decision are the same as Road Tour (as described earlier) (Figure 2). The transition to Double Decision presented short-term delays as we developed new recruitment and training materials for Double Decision and negotiated support for participants already using Road Tour to assure use of one format or the other, but not both by a single participant.

\section{Attention control}

Boatload of Crosswords (http://www./boatloadpuzzles.com) served as the attention control condition. Boatload of Crosswords is one of the oldest and most popular crossword puzzle games commercially available (Figure 3 ). The software offers the user a choice between three puzzle sizes, three levels of complexity, and varying font sizes. Boatload of Crosswords also provides optional help features, like filling in letters and words, showing incorrect letters or words in red, and solving the puzzle, that minimize frustration levels often associated with puzzle completion. Boatload of Crosswords was chosen for this study because, like Road Tour, it is computerized, very popular and easy to use; many older adults enjoy doing 


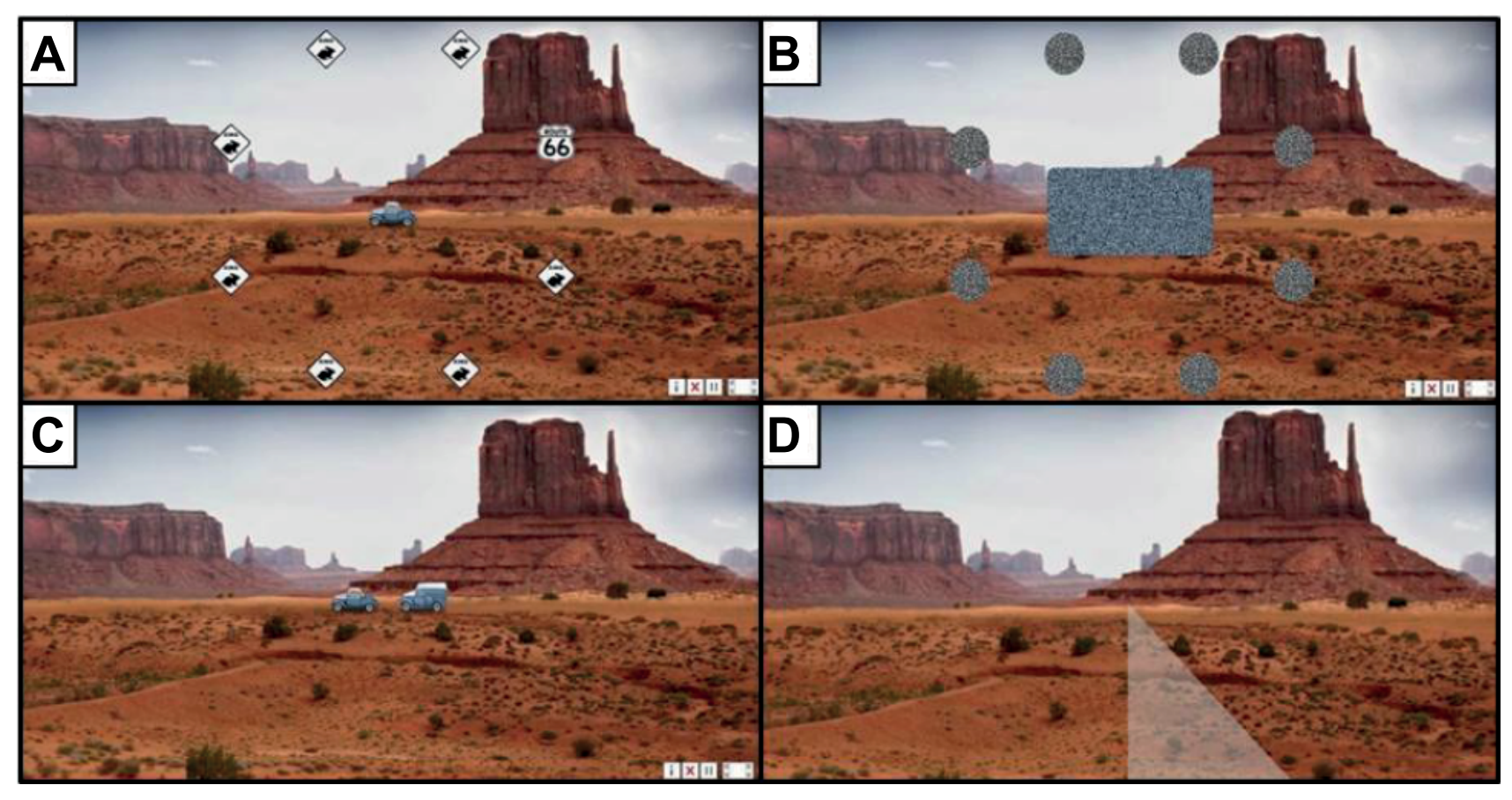

Figure 2 Double decision.

Notes: (A) Car or truck appears with seven distracters and Route 66 sign; (B) all disappear; (C) participant selects vehicle shown earlier; (D) participant identifies location of Route 66 sign. Available from: https://www.brainhq.com/why-brainhq/about-the-brainhq-exercises/attention/double-decision. ${ }^{49}$

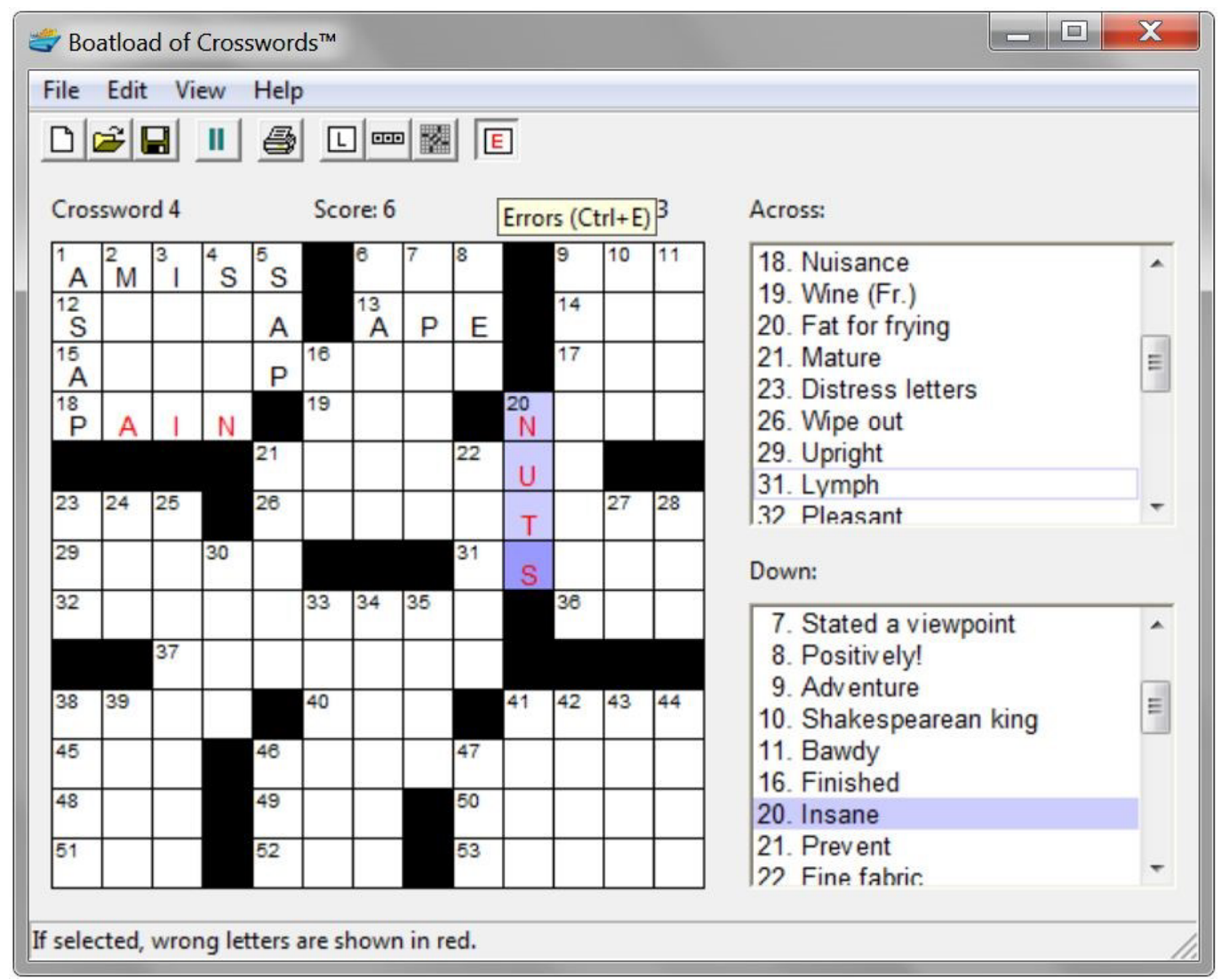

Figure 3 Boatload of Crosswords.

Notes: Available from: https://www.boatloadpuzzles.com/playcrossword. Version shown is with Error Assistance (E icon) turned on so that incorrect letters appear in red. Other icons shown are to print the puzzle, solve a letter, solve a word, and solve the puzzle..$^{50}$ 
crossword puzzles; and it was successfully used as the attention control condition in IHAMS.

\section{Analysis}

Descriptive statistics including Student's $t$-tests and $\chi^{2}$ analysis were used to compare the intervention and attention control groups at baseline and to examine differences based on living setting (AL vs IL). The original analysis plan was to evaluate the three specific aims using each person serving as his/her own control in linear panel analyses ${ }^{43}$ with GEE to correct for clustering within sites, and, logistic regression GEE models for binary outcomes. Power estimates were based on the results from the earlier IHAMS and ACTIVE studies. Setting a one-tailed $\alpha$ at 0.05 and allowing for $10 \%$ attrition, we estimated $\geq 80 \%$ power to detect the improvements in UFOV, $73 \%$ power to detect changes in depressive symptoms, and $68 \%$ power to detect suspected onset of clinical depression. All analyses were conducted using $I B M$ SPSS Software, v24.

\section{Adaptations to the analysis}

Because of the inclusion of participants from IL settings, the analytic approach was altered. We used random-effects general linear mixed models. The dependent variable was the outcome of interest at the time point of interest. The clustering (random-effects) variable was the AL or IL from each participating senior living community. The two main factors were intervention vs attention control and AL vs IL. The interaction between these two factors was included to test for heterogeneity of treatment effects between AL vs IL. Covariates included the outcome of interest at baseline, age, and sex.
Two ad hoc analyses for the first specific aim were also conducted. The first involved expanding the intervention vs attention control from a binary indicator to a trichotomous indicator of Road Tour vs Double Decision vs attention control to test for potential heterogeneity of treatment effects between two speed of processing platforms. The second involved opportunistic dosing testing based on whether the intervention participants completed 8 or more hours of intervention training vs $<8$ hours.

\section{Results}

A total of 31 senior living communities were engaged as partners in the study, including stand-alone AL residences, senior living programs that provided both AL and IL, settings licensed as residential care that provided services similar to AL, and "affordable AL" programs licensed by the state that offer Housing and Urban Development supported housing complimented with services offered by an independent agency. A total of 351 older adults were enrolled in the study, including 178 randomized to the crossword puzzle attention control group and 173 to the cognitive training (Road Tour/ Double Decision) intervention group.

\section{Demographics}

Characteristics of participants by group assignment are presented in Table 1. There were no statistically significant differences between the two groups with the exception of education. Participants' age ranged from 55 to 102, with mean age of 81 years. More than half $(63 \%)$ were 75 years or older. The vast majority were white, non-Hispanic (98\%) women $(74 \%)$ who lived alone $(>75 \%)$ and were widowed

Table I Participant characteristics at baseline by treatment group

\begin{tabular}{|c|c|c|c|c|}
\hline Participant characteristics ${ }^{a}$ & $\begin{array}{l}\text { Attention control group } \\
\text { Boatload of Crosswords } \\
\mathrm{N}=178\end{array}$ & $\begin{array}{l}\text { Intervention group } \\
\text { Road Tour/Double Decision } \\
\mathrm{N}=173\end{array}$ & $p$-value & $\begin{array}{l}\text { Total sample } \\
\mathbf{N}=35 \text { I }\end{array}$ \\
\hline \multicolumn{5}{|l|}{ Demographics } \\
\hline Age: Mean years & 81.3 & 80.7 & 0.519 & 81.0 \\
\hline Women & $72.5 \%$ & $75.1 \%$ & 0.519 & $73.8 \%$ \\
\hline Widowed & $51.1 \%$ & $54.3 \%$ & 0.749 & $52.7 \%$ \\
\hline White & $98.3 \%$ & $98.3 \%$ & 0.391 & $98.3 \%$ \\
\hline Latino/hispanic & $1.1 \%$ & $1.7 \%$ & 0.739 & $\mathrm{I} .4 \%$ \\
\hline Living alone & $75.8 \%$ & $76.9 \%$ & 0.819 & $76.4 \%$ \\
\hline $\mathrm{AL}$ & $46.6 \%$ & $47.4 \%$ & 0.885 & $47.0 \%$ \\
\hline Years in residence & & & 0.456 & \\
\hline$<$ I year & $28.7 \%$ & $30.6 \%$ & & $29.6 \%$ \\
\hline $\mathrm{I}-2$ years & $34.3 \%$ & $25.4 \%$ & & $29.9 \%$ \\
\hline $3-5$ years & $20.8 \%$ & $21.4 \%$ & & $21.1 \%$ \\
\hline 6 years or more & $16.3 \%$ & $22.5 \%$ & & $19.4 \%$ \\
\hline Range in years & $<1$ to 20 & $<1$ to 27 & & $<1$ to 27 \\
\hline
\end{tabular}

(Continued) 
Table I (Continued)

\begin{tabular}{|c|c|c|c|c|}
\hline Participant characteristics $^{a}$ & $\begin{array}{l}\text { Attention control group } \\
\text { Boatload of Crosswords } \\
\mathrm{N}=178\end{array}$ & $\begin{array}{l}\text { Intervention group } \\
\text { Road Tour/Double Decision } \\
\mathrm{N}=173\end{array}$ & $p$-value & $\begin{array}{l}\text { Total sample } \\
\mathbf{N}=35 \text { I }\end{array}$ \\
\hline \multicolumn{5}{|l|}{ Socioeconomic status } \\
\hline Education & & & 0.035 & \\
\hline Elementary school (Grades I-8) & $1.7 \%$ & $1.7 \%$ & & $1.7 \%$ \\
\hline Some high school (Grades 9-II) & $2.8 \%$ & $1.7 \%$ & & $2.3 \%$ \\
\hline High school/GED & $25.3 \%$ & $30.1 \%$ & & $27.6 \%$ \\
\hline Vocational/technical & $5.6 \%$ & $4.0 \%$ & & $4.8 \%$ \\
\hline Some college & $26.4 \%$ & $27.7 \%$ & & $27.1 \%$ \\
\hline College graduate & $18.0 \%$ & $24.9 \%$ & & $21.4 \%$ \\
\hline Graduate school & $20.2 \%$ & $9.8 \%$ & & $15.1 \%$ \\
\hline Annual income & & & 0.296 & \\
\hline$<\$ 10 K$ & $2.8 \%$ & $2.3 \%$ & & $2.6 \%$ \\
\hline$\$ 10 \mathrm{~K}$ to $<\$ 15 \mathrm{~K}$ & $5.6 \%$ & $5.8 \%$ & & $5.7 \%$ \\
\hline$\$ 15 \mathrm{~K}$ to $<\$ 20 \mathrm{~K}$ & $7.9 \%$ & $5.2 \%$ & & $6.6 \%$ \\
\hline$\$ 20 \mathrm{~K}$ to $<\$ 25 \mathrm{~K}$ & $8.4 \%$ & $9.2 \%$ & & $8.8 \%$ \\
\hline$\$ 25 \mathrm{~K}$ to $<\$ 35 \mathrm{~K}$ & $9.6 \%$ & $11.6 \%$ & & $10.6 \%$ \\
\hline$\$ 35 \mathrm{~K}$ to $<\$ 50 \mathrm{~K}$ & $18.0 \%$ & $11.6 \%$ & & $14.9 \%$ \\
\hline$\$ 50 \mathrm{~K}$ to $<\$ 75 \mathrm{~K}$ & $6.7 \%$ & $12.7 \%$ & & $9.7 \%$ \\
\hline$>\$ 75 \mathrm{~K}$ & 6.2 & $7.5 \%$ & & $6.8 \%$ \\
\hline Do not know/not certain & $28.7 \%$ & $26.0 \%$ & & $27.4 \%$ \\
\hline Pass (prefer to not answer) & $6.2 \%$ & $8.1 \%$ & & $7.1 \%$ \\
\hline Social support: Mean (total score $0-20$ ) & 13.9 & 14.1 & 0.235 & 14.0 \\
\hline \multicolumn{5}{|l|}{ Health history } \\
\hline Heart disease & $35.4 \%$ & $35.8 \%$ & 0.592 & $35.6 \%$ \\
\hline High blood pressure & $58.4 \%$ & $63.6 \%$ & 0.187 & $61.0 \%$ \\
\hline Stroke & $18.5 \%$ & $17.9 \%$ & 0.592 & $18.2 \%$ \\
\hline Diabetes & $26.4 \%$ & $24.9 \%$ & 0.740 & $25.6 \%$ \\
\hline Asthma & $14.0 \%$ & $12.7 \%$ & 0.715 & $13.4 \%$ \\
\hline Emphysema or COPD & $12.4 \%$ & $14.5 \%$ & 0.565 & $13.4 \%$ \\
\hline Arthritis & $60.7 \%$ & $65.9 \%$ & 0.457 & $63.2 \%$ \\
\hline Osteoporosis & $19.7 \%$ & $30.6 \%$ & 0.040 & $25.1 \%$ \\
\hline Chronic back problem/headaches & $36.0 \%$ & $41.0 \%$ & 0.396 & $38.5 \%$ \\
\hline Chronic pain (any problem) & $38.2 \%$ & $48.0 \%$ & 0.080 & $43.0 \%$ \\
\hline Cancer & $12.4 \%$ & $12.7 \%$ & 0.995 & $12.5 \%$ \\
\hline Kidney, bladder, bowel problems & $39.3 \%$ & $35.3 \%$ & 0.773 & $37.3 \%$ \\
\hline Parkinson's disease & $4.5 \%$ & $3.5 \%$ & 0.330 & $4.0 \%$ \\
\hline Glaucoma & $11.8 \%$ & $11.0 \%$ & 0.594 & $11.4 \%$ \\
\hline Other visual problems & $30.9 \%$ & $29.5 \%$ & 0.578 & $30.2 \%$ \\
\hline Hearing problems & $41.0 \%$ & $43.9 \%$ & 0.580 & $42.3 \%$ \\
\hline \multicolumn{5}{|l|}{ Psychiatric history } \\
\hline Anxiety disorder & $18.0 \%$ & $14.5 \%$ & 0.670 & $16.2 \%$ \\
\hline Depression or depressive disorder & $23.0 \%$ & $22.5 \%$ & 0.994 & $22.8 \%$ \\
\hline Takes medication to treat depression ${ }^{c}$ & $16.3 \%$ & $14.5 \%$ & 0.633 & $15.4 \%$ \\
\hline Uses other depression therapies ${ }^{d}$ & $11.8 \%$ & $15.0 \%$ & 0.875 & $13.4 \%$ \\
\hline
\end{tabular}

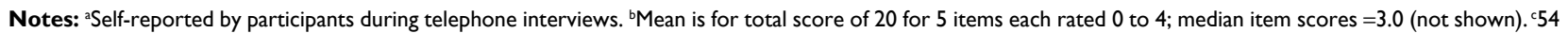
of 80 participants (67.5\%) who reported having depression also reported using medication interventions. ${ }^{\mathrm{d}} 47$ of 80 participants (58.8\%) who reported having depression also reported other therapies: talking with a therapist/counselor, exercise, self-help books, online resources, and other psychosocial approaches.

Abbreviations: AL, assisted living; GED, General Equivalency Diploma; COPD, chronic obstructive pulmonary disease.

(53\%). Most participants (60\%) reported living in the residence two or fewer years, while $21 \%$ reported $3-5$ years of residence, and 19\% reported living in the residence 6 or more years. Overall, the sample was highly educated, with $68 \%$ reporting having attended or graduated from college/ graduate school. In comparison of the groups, however, the attention control (crossword puzzle) group was significantly more educated. A third of participants did not know/were unsure of their annual income or opted to not report their income. Annual income ranged from $\$ 4,000$ to $\$ 200,000$, and more participants reported incomes of less than $\$ 25 \mathrm{~K} /$ $\mathrm{yr}(23.6 \%)$ than incomes of $\$ 50 \mathrm{~K}$ or more (16.6\%). Scores 
for social support suggest participants felt supported most of the time as the overall mean was 14.0 for the five items, with median scores of 3.0 for each item.

\section{Physical health history}

There were no statistically significant differences between groups in the report of 16 common physical health conditions, with the exception of osteoporosis that was more frequently reported in the intervention group. Participants reported from 0 to 11 health conditions with an average of 4.5 conditions. Twenty one percent (21\%) reported from zero to two, $69 \%$ reported three to seven, and $10 \%$ reported eight to 11 health conditions. The most commonly reported conditions were arthritis (63\%), high blood pressure $(61 \%)$, chronic pain (43\%), back problems and headaches $(39 \%)$, and problems with hearing and vision ( $43 \%$ each).

\section{Depression and anxiety history}

There were also no differences between groups in the report of anxiety and depression. Sixteen percent (16\%) of participants reported having anxiety disorder and $23 \%$ reported depression or depressive disorder. Of those reporting depression $(n=80), 67.5 \%$ indicated they were taking a medication to treat depression and $26 \%$ reported other therapies to treat depression, such as self-help books or other supports. Depression and anxiety were highly comorbid (75.4\% reported both) and thus correlated $(p<0.001)$.

\section{Study outcome measures}

There were no statistically significant differences in study outcomes at baseline, with the one exception (Table 2). Mean scores and percent distributions between the attention control (crossword puzzle) and intervention (Road Tour/Double

Table 2 Participant outcomes at baseline by treatment group

\begin{tabular}{|c|c|c|c|c|}
\hline Study outcomes $^{a}$ & $\begin{array}{l}\text { Attention control group: } \\
\text { Boatload of Crosswords } \\
N=178\end{array}$ & $\begin{array}{l}\text { Intervention group: Road } \\
\text { Tour/Double Decision } \\
\mathrm{N}=173\end{array}$ & $p$-value & $\begin{array}{l}\text { Total } \\
\text { sample }\end{array}$ \\
\hline \multicolumn{5}{|l|}{ Aim I: Cognitive processing speed } \\
\hline UFOV Composite score & 540.26 & 564.33 & 0.479 & 552.3 \\
\hline \multicolumn{5}{|l|}{ Aim 2: Depressive symptoms } \\
\hline PHQ-9 Score: Mean & 3.98 & 4.29 & $0.47 I$ & 4.1 \\
\hline PHQ-9 Depression severity levels & & & 0.443 & \\
\hline None & $64.2 \%$ & $62.5 \%$ & & $63.4 \%$ \\
\hline Mild & $28.9 \%$ & $28.6 \%$ & & $28.8 \%$ \\
\hline Moderate & $4.0 \%$ & $7.1 \%$ & & $5.5 \%$ \\
\hline Moderately severe & $2.9 \%$ & $1.2 \%$ & & $2.1 \%$ \\
\hline Severe & $0.0 \%$ & $0.6 \%$ & & $0.3 \%$ \\
\hline CESD-12 Score: Mean & 5.38 & 5.74 & 0.534 & 5.6 \\
\hline CESD-12 Threshold $>9$ & $20.8 \%$ & $25.4 \%$ & 0.302 & $23.1 \%$ \\
\hline \multicolumn{5}{|l|}{ Aim 3: Depression-related comorbidities } \\
\hline BPI interference score: Mean & 1.38 & 1.53 & 0.463 & 1.46 \\
\hline \multicolumn{5}{|l|}{ BPI severity: Means } \\
\hline Worst day & 2.49 & 3.05 & 0.058 & 2.77 \\
\hline Least day & 0.83 & 1.01 & 0.285 & 0.92 \\
\hline Average day & 1.68 & 2.33 & 0.005 & 2.01 \\
\hline Right now & 1.05 & 1.37 & 0.128 & 1.21 \\
\hline Pooled severity score & 1.50 & 1.94 & 0.035 & 1.72 \\
\hline GAD-7 Anxiety score: Mean & 2.20 & 2.75 & 0.116 & 2.48 \\
\hline GAD-7 Anxiety severity levels & & & 0.114 & \\
\hline None & $86.9 \%$ & $79.8 \%$ & & $83.4 \%$ \\
\hline Mild & $10.2 \%$ & $11.9 \%$ & & $11.1 \%$ \\
\hline Moderate & $1.7 \%$ & $6.5 \%$ & & $4.1 \%$ \\
\hline Severe & $1.1 \%$ & $1.8 \%$ & & $1.5 \%$ \\
\hline Self-rated health & & & 0.945 & \\
\hline Excellent & $7.9 \%$ & $6.9 \%$ & & $7.4 \%$ \\
\hline Very good & $34.3 \%$ & $34.1 \%$ & & $34.2 \%$ \\
\hline Good & $36.0 \%$ & $33.5 \%$ & & $34.8 \%$ \\
\hline Fair & $19.1 \%$ & $22.5 \%$ & & $20.8 \%$ \\
\hline Poor & $2.8 \%$ & $2.9 \%$ & & $2.9 \%$ \\
\hline
\end{tabular}

Notes: aSelf-reported by participants during telephone interviews. Self-rated health is one item from SF-36.

Abbreviations: SD, standard deviation; UFOV, Useful Field of View; PHQ-9, Patient Health Questionnaire, 9-item; CESD-12, Center for Epidemiological Studies Depression, 12 item; BPI, Brief Pain Interview; GAD-7, Generalized Anxiety Disorder, 7 item; SF-36, Short Form-36 Health Survey. 
Table 3 Comparison of baseline outcome measure by AL vs IL

\begin{tabular}{llll}
\hline Baseline outcome measures $^{\mathbf{a}}$ & AL & IL & p-value \\
\hline UFOV Composite score (ms) & $668 . I$ & 447.8 & 0.001 \\
PHQ-9 mean & 4.9 & 3.3 & 0.001 \\
CESD-I2 mean & 6.6 & 4.5 & 0.001 \\
GAD-7 mean & 3.0 & 1.9 & 0.003 \\
BPI Pooled severity score mean & 1.9 & 1.5 & 0.077 \\
BPI Interference score mean & 1.6 & 1.3 & 0.210 \\
Self-rated health & & & 0.001 \\
$\quad$ Excellent & $4.2 \%$ & $10.2 \%$ & \\
$\quad$ Very good & $25.5 \%$ & $43.5 \%$ & \\
$\quad$ Good & $38.8 \%$ & $32.2 \%$ & \\
$\quad$ Fair & $27.9 \%$ & $11.9 \%$ & \\
Poor & $3.6 \%$ & $2.3 \%$ & \\
\hline
\end{tabular}

Notes: ${ }^{a}$ Self-reported by participants during telephone interviews. Self-rated health is one item from SF-36.

Abbreviations: AL, assisted living; IL, independent living; UFOV, Useful Field of View; PHQ-9, Patient Health Questionnaire, 9-item; CESD-12, Center for Epidemiological Studies Depression, 12 item; GAD-7, Generalized Anxiety Disorder, 7 item; BPI, Brief Pain Interview; SF-36, Short Form-36 Health Survey.

Decision) groups were comparable for speed of processing (UFOV), depression, anxiety, pain interference, and level of self-rated health. The single difference between groups was mean BPI pain severity scores for the average day $(p=0.005)$.

\section{Study adaptations}

Three changes in the study were also examined at baseline. First, reducing the lower age boundary to 55 resulted in $2.3 \%$ of the overall sample being 55 to 59 years of age. Second, comparisons of participants based on their living setting (AL vs IL) indicated that there were statistically significant differences for nearly all main outcomes, as shown in Table 3. Significant differences are observed on the means for UFOV composite scores, the PHQ-9, CESD-12, GAD-7, and levels of self-reported health, but not pain (not shown).

\section{Discussion}

Three main themes related to the study implementation and baseline findings are notable. First, the successful use of a community-based design in which senior living staff were trained to function as RAs makes an important contribution to geriatric research methods. Several key advantages to the design are worthy of highlighting. The approach allowed the study to access residential care settings in a large geographic region that would have not otherwise been feasible to include due to the travel time demands. Engaging staff as RAs meant the "recruiter" already knew the older people in the setting; they did not need to build trust or establish their credibility. Finally, the successful inclusion of the "oldest-old" age group in a "computer study" addresses important biases related to the viability of persons over age 65 years in research studies, and persisting questions about older people's interest and ability to engage in technology.

The second main theme is that characteristics of participants in the attention control (crossword puzzles) and intervention (Road Tour/Double Decision) group were comparable with three exceptions: educational level, frequency of osteoporosis in the person's health history, and reports of pain severity for the average day. Thus, the randomization plan appears to have produced equivalent groups. Of equal importance, baseline characteristics of our sample provide important perspectives related to the composition of older adults that are attracted to senior living communities.

An important first consideration is that the average age of the sample ( 81 years) is considerably higher than earlier SOPT trials that report on depressive symptoms. Participants in the ACTIVE trial were an average of 74 years, ${ }^{22}$ and the average ages in IHAMS were 57 years (for the group aged 55-64) and 71 years (for the group $>65$ years) for an overall mean of 61 years for the sample at baseline. ${ }^{44}$ Consistent with being older, the current sample reported more health conditions (Means $=4.5$ vs 2.2 in ACTIVE) and were more likely to report fair or poor health ( $24 \%$ vs $14 \%$ in ACTIVE). ${ }^{22}$

Depression scores on the CESD-12 were also somewhat higher (means $=5.6$ vs 3.3 in ACTIVE). ${ }^{22}$ Overall, about a third of participants reported having depressive symptoms that are considered "subthreshold" as $28.8 \%$ experienced mild symptoms on the PHQ-9 and $23.1 \%$ had a score of 9 or greater on the 12-item CES-D. Although there is considerable variability in measures and definitions used, these findings are consistent with reports in the literature about depression in AL and other residential settings. ${ }^{8,45,46}$ Of interest, over a fifth of the sample ( $\mathrm{n}=80$ or $23 \%$ ) reported having depression, and many of these individuals reported taking medication $(68 \%)$ or were engaged in a psychosocial intervention (59\%). This finding is promising in light of challenges to depression detection and treatment in senior living settings. ${ }^{47}$

Depression-related factors were also generally low in the sample. The vast majority did not report current anxiety symptoms, and the $11 \%$ who did were in the mild range (5-9). Notably, 16\% reported having an anxiety disorder, and 43 of 57 (75.4\%) who reported anxiety also reported depression. This finding is consistent with reports emphasizing the clinical importance of comorbid anxiety and depression in older adults. ${ }^{4,48}$ Pain was also generally low; the mean score of 1.5 across the seven pain interference items (activity, mood, walking, normal work, relations with others, sleep, and enjoyment in life) suggests pain had little impact on daily life. Mean scores for the four severity items were consistently low, with the "worst day" being the highest with an average 
of 2.8 (where 10 is the worst possible pain). And while $24 \%$ reported their health as only fair or poor, the vast majority reported good, very good, or excellent health.

A third theme was that successful implementation of the community-based, partnership-style research project involved making changes in the design to best accommodate feedback and needs of partner organizations and "research in the field" challenges. Reducing the planned lower limit of age from 60 years to 55 years was particularly important to senior living communities classified as "affordable AL" that housed low income seniors aged 55 and older. As a result, only 2.3\% were in the range not originally planned (55-59 years), and the diversity of participant characteristics was likely enhanced by inclusion of seniors in affordable AL settings. For example, the report of annual income in this sample suggests lowerincome individuals were as well represented as the higherincome ones. Second, the change from Road Tour to Double Decision caused some short-term challenges as process issues were confirmed, but the impact on study outcomes appears inconsequential. Last, inclusion of IL programs resulted in differences in study outcomes at baseline that were not fully expected, but are important findings. Participants in AL settings had slower speed of processing (UFOV) scores, higher levels of depression and anxiety, and lower self-rated health compared to those in settings classified as IL, suggesting greater overall health challenges in this group. These findings will be further explored in study-related analyses by specific aim, will inform future research related to the composition of older adults in senior living communities, and hopefully will help shape both daily care practices related to health-related needs and use of cognitive training interventions.

\section{Conclusion}

To our knowledge, this is the first RCT to evaluate computerized SOPT in AL settings, and more specifically, the first to focus on depression and depressed-related outcomes associated with SOPT. Our study contributes to the growing body of literature about computerized cognitive training interventions for older adults, and most importantly, to the use of this training among the generally older individuals who have chosen senior living settings as their preferred housing option.

\section{Ethics approval and informed consent}

Institutional Review Board approval of the study protocol was obtained through the university committee for biomedical research (IRB-01), \#201208786. This committee has provided continuous oversight and monitoring. The research protocol was registered at ClinicalTrials.gov before any participants were approached for enrollment and was updated throughout the study.

\section{Acknowledgment}

Study staff Chelsea Green, RA, and Christine Haedtke, graduate RA, assisted in engaging senior living programs, training on-site RAs, and conducting interviews. Dr Linda Hand, Linda Thomsen, Dianne Rasch, and Maria Hein, Office of Nursing Research and Scholarship, provided post-grant assistance with data, financial, and report management. The authors acknowledge and appreciate the senior living communities that acted as partners in the study, the many staff who served as on-site RAs during the RCT, and particularly the older adults, many of whom had no prior computer experience, who engaged in computerized cognitive training and completed assessments over their year of involvement. This study was funded by the National Institute for Nursing Research Award \# NIH R01-NINR13908. Posit Science Corporation provided free copies of Road Tour and Double Decision for use by participants but had no role in the design and conduct of the study, or any manuscripts submitted for publication. Licenses for Boatload of Crosswords were purchased from Boatload Puzzles, LLC using NINR grant funds.

\section{Author contributions}

All authors were actively involved throughout the 5-year study and in all aspects of preparing this paper for publication. Dr Smith, Principal Investigator; Dr Jones, Study Biostatistician; Ms Dotson, Study Coordinator, and Dr Wolinsky, Coinvestigator and Methodologist, each made substantial contributions to: 1) the conception and design of the study, or acquisition of the data, or analysis and interpretation of the data; and 2) drafting the article or revising it critically for important intellectual content. Moreover, they have each 3) granted final approval of the current version for submission to be published, and 4) agree to be accountable for all aspects of the work. Accordingly, all authors meet the criteria for authorship as stated in the ICMJE's Uniform Requirements for Manuscripts Submitted to Biomedical Journals.

\section{Disclosure}

From December 2007 to March 2009 Dr Wolinsky had a part-time consulting arrangement (15 days total) with Posit Science Corporation to support additional analyses of the first five-years of the ACTIVE follow-up data that had not been identified in the original protocols nor funded by the various NIH grants. That arrangement was approved in advance by 
the ACTIVE Executive Committee (which included the NIH project officers), and was approved by the Provost of the University of Iowa. Since 2009, Dr Wolinsky has received no compensation of any kind from Posit Science Corporation. The authors report no other conflicts of interest in this work.

\section{References}

1. World Health Organization. Depression: Fact Sheet; 2017. Available from: http://www.who.int/mediacentre/factsheets/fs369/en/.

2. Chang YC, Yao G, Hu SC, Wang JD. Depression affects the scores of all facets of the WHOQOL-BREF and may mediate the effects of physical disability among community-dwelling older adults. PloS One. 2015;10(5):e0128356.

3. Deschenes SS, Burns RJ, Schmitz N. Associations between depression, chronic physical health conditions, and disability in a community sample: a focus on the persistence of depression. J Affect Disord. 2015;179:6-13.

4. Lerman SF, Rudich Z, Brill S, Shalev H, Shahar G. Longitudinal associations between depression, anxiety, pain, and pain-related disability in chronic pain patients. Psychosom Med. 2015;77(3):333-341.

5. Unutzer J, Schoenbaum M, Katon WJ, et al. Healthcare costs associated with depression in medically Ill fee-for-service medicare participants. J Am Geriatr Soc. 2009;57(3):506-510.

6. Gimm GW, Kitsantas P. Falls, depression, and other hospitalization risk factors for adults in residential care facilities. Int J Aging Hum Dev. 2016;83(1):44-62.

7. Watson LC, Lehmann S, Mayer L, et al. Depression in assisted living is common and related to physical burden. Am J Geriatr Psychiatry. 2006;14(10):876-883.

8. Kozar-Westman M, Troutman-Jordan M, Nies MA. Successful aging among assisted living community older adults. J Nurs Scholarsh. 2013;45(3):238-246.

9. Abrams RC, Nathanson M, Silver S, Ramirez M, Toner JA, Teresi JA. A training program to enhance recognition of depression in nursing homes, assisted living, and other long-term care settings: description and evaluation. Gerontol Geriatr Educ. 2017;38(3):325-345.

10. Bruhl KG, Luijendijk HJ, Muller MT. Nurses' and nursing assistants' recognition of depression in elderly who depend on long-term care. $J$ Am Med Dir Assoc. 2007;8(7):441-445.

11. Kramer D, Allgaier AK, Fejtkova S, Mergl R, Hegerl U. Depression in nursing homes: prevalence, recognition, and treatment. Int J Psychiatry Med. 2009;39(4):345-358.

12. McCabe MP, Karantzas GC, Mrkic D, Mellor D, Davison TE. A randomized control trial to evaluate the beyondblue depression training program: does it lead to better recognition of depression? Int J Geriatr Psychiatry. 2013;28(3):221-226.

13. Freiheit EA, Hogan DB, Strain LA, et al. Operationalizing frailty among older residents of assisted living facilities. BMC Geriatr. 2011;11:23.

14. Gobbens RJ, Krans A, van Assen MA. Validation of an integral conceptual model of frailty in older residents of assisted living facilities. Arch Gerontol Geriatr. 2015;61(3):400-410.

15. Hogan DB, Freiheit EA, Strain LA, et al. Comparing frailty measures in their ability to predict adverse outcome among older residents of assisted living. BMC Geriatr. 2012;12:56.

16. Stock KJ, Amuah JE, Lapane KL, Hogan DB, Maxwell CJ. Prevalence of, and resident and facility characteristics associated with antipsychotic use in assisted living vs. long-term care facilities: a cross-sectional analysis from Alberta, Canada. Drugs Aging. 2017;34(1):39-53.

17. Centers for Disease Control. CDC Promotes public health approach to address depression among older adults. Available from: https://www. cdc.gov/aging/pdf/cib_mental_health.pdf. Accessed February 28, 2018.

18. Franck L, Molyneux N, Parkinson L. Systematic review of interventions addressing social isolation and depression in aged care clients. Qual Life Res. 2016;25(6):1395-1407.
19. Fuentes D, Aranda MP. Depression interventions among racial and ethnic minority older adults: a systematic review across 20 years. $\mathrm{Am}$ J Geriatr Psychiatry. 2012;20(11):915-931.

20. Smits F, Smits N, Schoevers R, Deeg D, Beekman A, Cuijpers P. An epidemiological approach to depression prevention in old age. Am J Geriatr Psychiatry. 2008;16(6):444-453.

21. Wolinsky FD, Vander Weg MW, Martin R, et al. The effect of speed-ofprocessing training on depressive symptoms in ACTIVE. J Gerontol A Biol Sci Med Sci. 2009;64(4):468-472.

22. Wolinsky FD, Mahncke HW, Weg MW, et al. The ACTIVE cognitive training interventions and the onset of and recovery from suspected clinical depression. J Gerontol B Psychol Sci Soc Sci. 2009;64(5): 577-585.

23. Wolinsky FD, Vander Weg MW, Howren MB, et al. Interim analyses from a randomised controlled trial to improve visual processing speed in older adults: the Iowa Healthy and Active Minds Study. BMJ Open. 2011;1(2):e000225.

24. Wolinsky FD, Unverzagt FW, Smith DM, Jones R, Stoddard A, Tennstedt SL. The ACTIVE cognitive training trial and health-related quality of life: protection that lasts for 5 years. J Gerontol A Biol Sci Med Sci. 2006;61(12):1324-1329.

25. Merzenich M. Soft-Wired: How the New Science of Brain Plasticity Can Change Your Life. 2nd ed. San Francisco, CA: Parnassas Publishing; 2013.

26. Edwards JD, Vance DE, Wadley VG, Cissell GM, Roenker DL, Ball KK. Reliability and validity of useful field of view test scores as administered by personal computer. J Clin Exp Neuropsychol. 2005;27(5): 529-543.

27. Edwards JD, Ross LA, Wadley VG, et al. The useful field of view test: normative data for older adults. Arch Clin Neuropsychol. 2006;21(4): 275-286.

28. Kohout FJ, Berkman LF, Evans DA, Cornoni-Huntley J. Two shorter forms of the CES-D (Center for Epidemiological Studies Depression) depression symptoms index. J Aging Health. 1993;5(2):179-193.

29. Radoff LS. The CES-D Scale: a self-report depression scale for research in the general population. Appl Psychol Meas. 1977;1(3):385-401.

30. Wolinsky FD, Vander Weg MW, Howren MB, Jones MP, Dotson MM. The effect of cognitive speed of processing training on the development of additional IADL difficulties and the reduction of depressive symptoms: results from the IHAMS randomized controlled trial. J Aging Health. 2015;27(2):334-354.

31. Kroenke K, Spitzer RL, Williams JB. The PHQ-9: validity of a brief depression severity measure. J Gen Intern Med. 2001;16(9): 606-613.

32. Fine TH, Contractor AA, Tamburrino M, et al. Validation of the telephone-administered PHQ-9 against the in-person administered SCID-I major depression module. J Affect Disord. 2013;150(3):1001-1007.

33. Pinto-Meza A, Serrano-Blanco A, Penarrubia MT, Blanco E, Haro JM. Assessing depression in primary care with the PHQ-9: can it be carried out over the telephone? J Gen Intern Med. 2005;20(8):738-742.

34. American Psychiatric Association. Diagnostic and Statistical Manual of Mental Disorders (DSM-5). 5th ed. Arlington, VA: American Psychiatric Association; 2013.

35. Manea L, Gilbody S, McMillan D. Optimal cut-off score for diagnosing depression with the Patient Health Questionnaire (PHQ-9): a metaanalysis. CMAJ. 2012;184(3):E191-E196.

36. Beusterien KM, Steinwald B, Ware JE Jr. Usefulness of the SF-36 Health Survey in measuring health outcomes in the depressed elderly. J Geriatr Psychiatry Neurol. 1996;9(1):13-21.

37. Jenkinson C, Layte R, Jenkinson D, et al. A shorter form health survey: can the SF-12 replicate results from the SF-36 in longitudinal studies? J Public Health Med. 1997;19(2):179-186.

38. Atkinson TM, Rosenfeld BD, Sit L, et al. Using confirmatory factor analysis to evaluate construct validity of the Brief Pain Inventory (BPI). J Pain Symptom Manage. 2011;41(3):558-565.

39. Cleeland CS, Ryan KM. Pain assessment: global use of the Brief Pain Inventory. Ann Acad Med Singapore. 1994;23(2):129-138. 
40. Cleeland CS. The Brief Pain Inventory User Guide. Houston, TX: The University of Texas M. D. Anderson Cancer Center; 2008.

41. Spitzer RL, Kroenke K, Williams JB, Lowe B. A brief measure for assessing generalized anxiety disorder: the GAD-7. Arch Intern Med. 2006;166(10):1092-1097.

42. American Psychiatric Association. Diagnostic and Statistical Manual of Mental Disorders (DSM-IV). 4th ed. Arlington, VA: American Psychiatric Association; 2000.

43. Kessler RC, Gerrenberg DF. Linear Panel Analysis. New York, NY: Wiley; 1981.

44. Wolinsky FD, Vander Weg MW, Howren MB, Jones MP, Dotson MM. Effects of cognitive speed of processing training on a composite neuropsychological outcome: results at one-year from the IHAMS randomized controlled trial. Int Psychogeriatr. 2016;28(2):317-330.

45. Martin JL, Fiorentino L, Jouldjian S, Josephson KR, Alessi CA. Sleep quality in residents of assisted living facilities: effect on quality of life, functional status, and depression. JAm Geriatr Soc. 2010;58(5):829-836.
46. Adams KB, Moon H. Subthreshold depression: characteristics and risk factors among vulnerable elders. Aging Ment Health. 2009;13(5): 682-692.

47. Beuscher L, Dietrich M. Depression training in an assisted living facility: A Pilot Study. J Psychosoc Nurs Ment Health Serv. 2016;54(5): 25-31.

48. Bair MJ, Poleshuck EL, Wu J, et al. Anxiety but not social stressors predict 12-month depression and pain severity. Clin J Pain. 2013; 29(2):95-101.

49. Posit Science. Double Decision. San Francisco, CA: Posit Science Corporation. Available from: https://www.brainhq.com/why-brainhq/ about-the-brainhq-exercises/attention/double-decision. Accessed 28 February 2018.

50. Boatload Puzzles. Boatload of Crosswords. Yorktown Heights: Boatload Puzzles, LLC. Available from: https://www.boatloadpuzzles.com/ playcrossword. Accessed 28 February 2018.
Open Access Journal of Clinical Trials

\section{Publish your work in this journal}

The Open Access Journal of Clinical Trials is an international, peerreviewed, open access journal publishing original research, reports, editorials, reviews and commentaries on all aspects of clinical trial design, management, legal, ethical and regulatory issues, case record form design, data collection, quality assurance and data auditing

\section{Dovepress}

methodologies. The manuscript management system is completely online and includes a very quick and fair peer-review system, which is all easy to use. Visit http://www.dovepress.com/testimonials.php to read real quotes from published authors. 